\title{
O Direito Das Gentes Como Discurso: O Tráfico Internacional De Escravos Sob A Luz Do Saber Jurídico (1839-1850)
}

\author{
Gustavo Pinto de Sousa * \\ Instituto Nacional de Educação de Surdos (INES), Departamento de Ensino \\ Superior (DESU/INES), Laranjeiras, Rio de Janeiro, Brasil.
}

ORCID https://orcid.org/0000-0002-7539-2497

\begin{abstract}
Resumo: O presente artigo tem como objetivo analisar a literatura jurídica sobre o direito das gentes e seus efeitos jurídicos no debate internacional sobre a supressão do tráfico de escravos. Nesse sentido, a análise perseguirá como a literatura dos manuais de direito oitocentista debruçaram-se acerca dos elementos de Direito das Gentes para balizar as disputas jurídicas em relação às regras internacionais das nações no século XIX. Sendo assim, o palco das disputas do Direito das Gentes levará em consideração as contendas políticas e jurídicas que envolveram países como Brasil, Portugal e Inglaterra no que tange aos problemas sobre a interrupção do tráfico de escravos pelas águas do Atlântico Sul. Em termos metodológicos, o texto parte das contribuições da análise do discurso na vertente francesa. Ilumina-se nas fontes a produção dos sentidos jurídicos em relação ao Direito das Gentes. Ademais, o artigo iluminará um entrecruzamento interdisciplinar e metodológico entre a História e o Direito ao tomar o Direito das Gentes como um discurso/saber. Por fim, o texto apresentará como as regras do Direito Internacional foram utilizadas para dar um sentido de legalidade, legitimidade e justiça em relação a permanência ou não do tráfico internacional de escravos.
\end{abstract}

Palavras-chave: Direito das Gentes. Tráfico Internacional de Escravos. Comparação histórica e jurídica. Discurso.

* Professor Adjunto no Departamento de Ensino Superior no Instituto Nacional de Educação de Surdos (DESU/INES).

E-mail: gsousarj@gmail.com

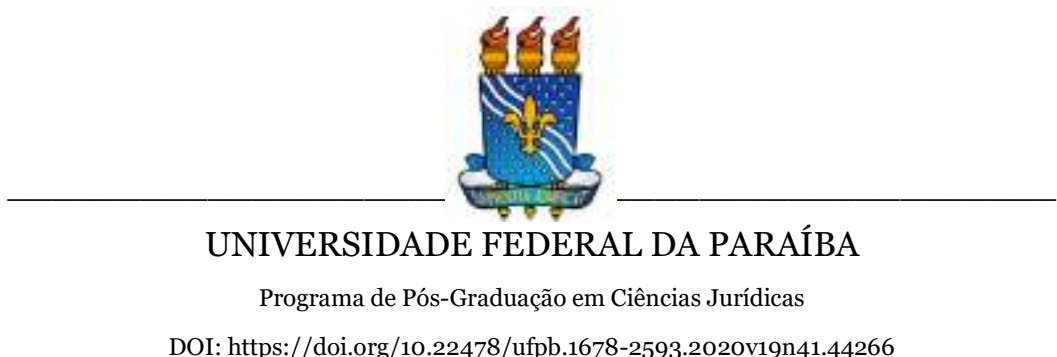




\title{
O Direito Das Gentes Como Discurso: O Tráfico Internacional De Escravos Sob A Luz Do Saber Jurídico (1839-1850)
}

Gustavo Pinto de Sousa

\section{CONSIDERAÇÕES INICIAIS}

\author{
[...] ius gentium significava "a lei \\ comum das nações", ou seja, uma \\ convenção que foi um apêndice do \\ direito civil e destinava-se a facilitar \\ as relações com os estrangeiros. Mais \\ tarde, ius gentium foi denotando usos \\ comuns observados no comércio e nas \\ relações em geral ${ }^{1}$. \\ (CÍCERO, por LETWIN, 2005, p. 43) \\ Jamais pode uma soberania firmar-se \\ em detrimento de outra soberania. \\ (ROUSSEFF, 2013)
}

Um homem e uma mulher de tempos históricos diferentes. Cícero, pensador romano, discutia a pertinência da lei na organização da Roma republicana. Em seus estudos, o paralelo entre e lei e razão eram condições fundamentais para as relações sociais e o funcionamento da República. Entre lex e ius, Cícero considerava a primeira como a lei escrita, na qual seu direcionamento era normativo e autoritário, enquanto o ius aproximava-se dos costumes, das formas não escritas e das prescrições das ideias. Em suma, o ius contemplava

\footnotetext{
1 Tradução nossa.
} 
aspectos do direito natural de respeito aos costumes, e a lex tinha por objetivo o ordenamento e a disciplinarização da sociedade.

O ius gentium, no sentido de Cícero, era um campo de saber jurídico no qual havia um direito comum das e paras as "nações". Sua logicidade tem por finalidade um arranjo de um "direito civil comum" para "irmandade". Assim, ele arbitraria as diferenças entre os povos. Seu ius gentium tem por escopo harmonizar as relações jurídicas entre as diversas "gentes" no plano exterior, isto é, era uma forma de Roma se concatenar com os "outros".

No episódio de denúncia do grupo Wikileaks (2013), de espionagem da presidenta Dilma Rousseff pelo governo Barack Obama, azedaram as relações diplomáticas entre Brasil e Estados Unidos. Na ocasião, estava programada uma visita oficial da mandatária brasileira aos Estados Unidos, que foi cancelada em virtude da publicação do Wikileaks.

A resposta brasileira, na época, ocorreu no Debate Geral da 68 $\underline{a}$ Assembleia Geral das Nações Unidas, em Nova York, quando Dilma Rousseff expôs que nenhuma soberania deveria ser firmada em desvantagem de outrem. Essa recente contenda só foi resolvida em junho de 2015, quando a presidenta e Obama encontraram-se em Washington em uma visita de quatro dias, na qual discutiram temas como comércio, defesa e educação.

Distintos no tempo e no espaço, Cícero e Rousseff protagonizaram uma cena comum para este artigo: o uso político do direito das gentes. Ambos reclamavam que a "lei comum das nações" deveria ser respeitada, pois seu objetivo era facilitar as relações entre os estrangeiros. Ademais, quando se comparam esses dois atores, temse como proposta a elaboração de um mosaico discursivo do direito das gentes. Não uma verticalização dos teóricos sobre o direito das gentes, mas uma experimentação dos sentidos acerca desse campo jurídico.

A problematização de um mosaico discursivo seguiu as orientações de Michel Foucault nos estudos a respeito do que é 
discurso e enunciado. Para ele, uma formação discursiva leva em consideração "uma regularidade (ordem, correlações, posições e funcionamentos, transformações) (FOUCAULT, 2009, p.43)" que tem como objetivo explicar "como e por quê" do ordenamento dos objetos. Em linhas gerais, a análise dos manuais de direito das gentes como um conjunto de enunciados jurídicos propõe-se explicar as regras do jogo. Ou, como observou o "filósofo-historiador", entender "o conjunto das regras que tornaram possíveis, simultânea ou sucessivamente, descrições puramente perceptivas (FOUCAULT, 2009, p.38)". Por isso, o discurso jurídico acerca do direito das gentes constitui-se em um conjunto de enunciados que estavam na materialidade dos manuais. Por sua vez, esse discurso/saber operou com as precauções de como deveriam se comportar as nações no plano internacional.

Entre os mais variados períodos históricos, a relação entre as "gentes" necessitou ser equacionada em razão dos interesses, que nem sempre eram comuns. Assim, proponho uma narrativa de enunciações que investigaram o campo do direito das gentes como horizonte de estudo. Dessa forma, o fio condutor deste texto será a análise de como os autores publicistas entendiam o direito das gentes nos manuais jurídicos do século XIX e quais eram suas matrizes teóricas.

Portanto, é importante mencionar que essas verificações partem de como os juristas avaliaram a questão. Assim, o direito internacional, como afirmam Accioly, Silva e Casella (2011, p.48), era uma esfera de conhecimento bidimensional, uma vez que tratava de querelas provenientes da terra e do mar, quando os "Estados" questionavam suas redes de poder. E por que esses autores? A justificativa é que na maior parte da bibliografia usada pelos juristas do direito das gentes no século XIX, e que serão objeto de análise, esses homens aparecem referenciados como matrizes de pensamento. Sendo assim, no tópico abaixo se discutirá como os juristas lidaram com as questões relativas ao saber jurídico do Direito das Gentes. 


\section{UM MOSAICO DISCURSIVO DO IUS GENTIUM NOS MANUAIS JURÍDICOS}

Nos manuais jurídicos oitocentistas brasileiros e portugueses de Silvestre Pinheiro Ferreira (1834), Vicente Ferrer Neto Paiva (1839) e Pedro Autran da Malta Albuquerque (1851), os chamados "autores modernos", da perspectiva da escolástica medieval e da filosofia do direito alemã, aparecem como matrizes discursivas dos problemas do direito das gentes.

No texto de Pinheiro, destaca-se o diálogo com as ferramentas de direito das gentes de Francisco de Vitória, Christian Wolff e Emmerich von Vattel, enquanto, nos escritos de Paiva, a filosofia do direito alemã, composta por autores como Cornelius van Bynkershoek, Samuel Pufendorf e Cristian Wolff e Albuquerque, que, no título de seu manual, indicava que seu estudo estava embasado "segundo as doutrinas dos escritores modernos", estabelecendo interseções com Vitória, Grócio, Pufendorf, Bynkershoek, Vattell, J. J. Burlamarqui e Georg-Friedrich von Marten, e, em certa medida, com Jeremy Bentham.

Francisco de Vitória (1458-1546) considerava que a presença dos Estados constituía uma unidade. Denominada por ele orbe, a função do direito das gentes era "compreender as normas que a razão natural estabeleceu entre as nações" (ACCIOLY \& OUTROS, 2011, p. 74). A orbe seria uma comunidade internacional jurídica e moral na qual existiria uma interdependência entre as nações. Em Vitória, o direito das gentes não é apenas a constituição de um pacto estabelecido entre os homens e as nações. Ele fornecia as condições necessárias para o funcionamento da lei, pois, se existe um pacto de homens no corpo interno da nação, ele poderia ser, externamente, respeitado pelo bom desempenho da orbe. 
A partir disso, há em Francisco de Vitória uma relação entre direito das gentes e direito natural, pois, enquanto o primeiro se propõe a universalidade, o segundo se constituiria na "garantia" e nos "deveres" que cada grupo social pratica no universo da cultura jurídica. Nesse sentido, os escritos de Vitória tiveram como alvo a experiência espanhola na conquista da América, em que ele fazia críticas às formas de dominação. Portanto, defendia a tese da orbe, pois não acreditava no isolamento das "gentes" de forma inorgânica. Para ele, os povos estavam vinculados tanto pelo direito natural quanto pelo direito das gentes. Ou, como afirmou Accioly, Silva e Casela, havia uma interligação pelo "estado de natureza e pelo contrato social" (ACCIOLY \& OUTROS, 2011, p. 74).

Hugo Grócio (1583-1645), ao contrário da formação escolástica de Vitória, fundamentou o direito das gentes como um universo de estudo científico. Autor do livro Mare liberum, publicado em 1608 a pedido da Companhia Holandesa das Índias Orientais, o texto era uma crítica ao monopólio de rotas marítimas e territórios conquistados por Estados modernos como Portugal, Espanha e Inglaterra. Nas tramas do livro, Grócio questionava o uso dos mares por esses Estados e defendia a liberdade de navegação e comércio.

Nele, o direito das gentes era definido como uma regra em que "todas as gentes podem [se] relacionar e negociar entre si" (PADOIN, 2013, p.124). Como destacou Padoin, "os que restringiam o direito das gentes de terem a liberdade restringiam a própria condição do ser humano" (PADOIN, 2013, p.124). Há em Grócio, assim como em Vitória, uma inter-relação entre o direito das gentes e o direito natural, na qual o desrespeito mútuo de ambos era uma violação à natureza. A premissa do mar como espaço não disciplinarizado era definida por Grócio desta forma: "Deus que rodeou as terras do oceano por todas as partes o fez navegável, e os ventos violentos ou pacíficos não soprando sempre na mesma região" (PADOIN, 2013, p.124), ou seja, sob o oceano não poderia haver jurisprudência governamental.

Sem incorrer em anacronismo, o princípio dos bills Palmerston e Aberdeen - ignorava os escritos de Mare liberum 
defendidos por Grócio. Na contramão desse autor, a política de supressão do tráfico de escravos defendida pelos britânicos disciplinarizar a partir das práticas de governamentalidade o uso do oceano Atlântico, tratando-o como um problema a ser resolvido pela pressão marítima britânica.

Samuel Pufendorf (1632-1694), pela via do jusnaturalismo racionalismo, natureza e individualismo -, seguia as orientações de Grócio ao defender que o direito das gentes era um campo de conhecimento assentado no direito natural. Em seus trabalhos, a noção de igualdade jurídica dos Estados foi o fio condutor da definição de direito das gentes como um "direito interestadual" embasado na razão. Seu ímpeto em secularização do direito das gentes afastava-se do sentido escolástico.

Cornelius van Bynkershoek (1673-1743), na orientação do direito positivo, assim como Pufendorf, definia o direito das gentes como um direito interestatal. E como Grócio, defendia que os oceanos eram espaços de livre navegação. Entretanto, inaugura a tese de que, "se o alto-mar não pode ser reclamado por nenhum Estado, a faixa de mar próxima da costa pode ser reclamada pelo Estado costeiro" (ACCIOLY \& OUTROS, 2011, p. 92), ou seja, Bynkershoek instaurou o princípio da linha de respeito medida em muitos dos escritos oitocentistas como o alcance de um tiro de canhão.

Christian Wolff (1679-1754), na constituição da "civita maxima", definia uma espécie de "quase pacto", no qual deveria existir uma cooperação entre os indivíduos e a nação em prol da segurança. Para ele, a fórmula do direito das gentes consistia em que "as sociedades, os povos, as nações são pessoas jurídicas, que entram em estado de independência natural, mas mesmo assim obrigadas a cumprir umas em relação às outras com os deveres da humanidade $\mathrm{e}$ da caridade" (ACCIOLY \& OUTROS, 2011, p. 97). Em suma, o direito das gentes, em Wolf, reunia as noções do direito natural, do mesmo modo que das relações de poder e do direito civil. Foi dessa correlação entre direito natural e direito civil aplicado às nações que o próximo 
“autor moderno" esboçar o raciocínio de um direito das gentes necessário.

Emmerich von Vattel (1714-1767) foi um dos autores mais referenciados entre os manuais jurídicos acerca do direito das gentes. Von Vattel argumentava que a relação entre os Estados era pautada por suas soberanias. Como pontuam Aciolly, Silva e Casella, "os Estados se fazem os únicos juízes de seus atos, de seus direitos e deveres" (ACCIOLY \& OUTROS, 2011, p. 99-100). Isto é, a igualdade soberana dos Estados funcionava como princípio norteador do direito das gentes. Segundo Von Vattel, “o direito das gentes é a ciência do direito que tem lugar entre nações ou Estados, assim como das obrigações correspondentes a esse direito" (VATTEL, 2004, p.1).

Von Vattel, que tratava a nação como uma pessoa jurídica, entendia que a aplicação do direito das gentes passava por executar as regras do direito natural às nações. Ele compreendia que o direito das gentes emergia como "um direito da natureza aplicado às nações" (VATTEL, 2004, p.2). Entretanto, atenta para que o direito natural não era praticado de forma idêntica por todos, por isso considerava que era preciso construir um ideal comum das regras básicas de convivência. De certa forma, esse problema do direito natural foi colocado em pauta com a legitimidade ou não do tráfico intercontinental e da escravidão no século XIX. Se antes ela era aceita, como cobrar a partir de então que a escravidão era um atentado ao direito natural e, consequentemente, ao direito das gentes?

Nesse sentido, Vattel entendia o direito das gentes como necessário, no qual o direito natural "universalizado" seria aplicado às nações. E por que necessário? Para ele, seria uma forma de harmonizar a obrigação entre as "pessoas jurídicas" - as nações - perante os direitos e deveres. Assim, em caso de desrespeito ao direito das gentes, afirmava que "todas as nações estão no direito de reprimir pela força aquela que viole abertamente as leis da sociedade que a Natureza entre elas estabeleceu" (VATTEL, 2004, p.10).

$\mathrm{Na}$ definição de direito das gentes positivo, Vattel condicionou três subdivisões para esse campo: o direito das gentes voluntário, 
convencional e costumeiro. O primeiro era o reconhecimento de que as nações são livres, independentes e iguais. A partir dessas prerrogativas, caberia a elas projetar esse sentimento ao plano externo com o escopo de equilibrar a "administração de seus negócios e na busca de suas pretensões" (VATTEL, 2004, p.9).

O direito das gentes convencional, ou direito dos tratados, consistia nos "diversos compromissos que as nações podem assumir [e que] produzem uma nova espécie de direito das gentes, que se chama convencional, ou dos tratados" (VATTEL, 2004, p.10). Para Vattel, essa modalidade não tem caráter universalizante, mas de foro particular, obrigando, portanto, as partes contratantes a segui-lo. Essa forma de direito dos tratados, ou melhor, sua validade foi usada como compromisso jurídico pelos personagens envolvidos nessa trama.

Já o direito das gentes costumeiro funcionaria como um jogo de "certos princípios e práticas" (VATTEL, 2004, p.11), que era consensual entre as nações, ou, como Vattel denominava, de "costumes das nações". Ele considerava que o direito das gentes costumeiro não era universal, sendo subordinando apenas às nações que o adotaram a partir de convenções como o Congresso de Viena, em 1815, a exercitar tal norma.

Nessa mesma escala, os bills podem ser usados como exemplos de direito das gentes costumeiro, pois foi uma tentativa de transformar no Brasil e Portugal a condenação moral do tráfico de escravos, seja pela via da filantropia, seja pela via da humanidade. Resumidamente, como discorreu Maria Medianeira Padoin, Vattel foi presença pela Ibero-América, nas faculdades de direito e em seus manuais jurídicos.

J. J. Burlamaqui (1694-1748) defendeu que entre as nações deveria existir uma lei que servisse de orientação para o comércio, que na maioria das vezes era a atividade que fazia com que os governos estabelecem relações. A lei das nações seguiria o princípio de Thomas Hobbes, em que a lei natural dos Estados seria a definição do direito das gentes. Logo, ela seria inerente aos povos, e os chefes de Estado 
seriam os mecanismos utilizados para cuidar dos interesses das "gentes".

Georg-Friedrich von Martens (1756-1821), considerado historicista do direito das gentes, buscou defini-lo como uma forma de solidariedade. Para ele, "o direito das gentes, fundado no direito natural, reconhece aos Estados direitos fundamentais" (ACCIOLY \& OUTROS, 2011, p. 103). E o que seriam esses "direitos fundamentais"? $\mathrm{O}$ respeito às regras do direito natural, que para ele tinham pretensão à universalidade.

O Manual do cidadão em um governo representativo ou princípios de direito constitucional, administrativo e das gentes, de autoria de Silvestre Pinheiro Ferreira, foi publicado em Paris em 1834. De maneira geral, o ex-conselheiro de d. João VI, em seus escritos, discutia as bases de um Estado liberal e constitucional, assim como propostas reformistas ao Estado absolutista português. Ele debruçouse sobre a nova construção do Estado português, pós-Independência do Brasil. Segundo Alexandro Ferreira de Souza, a relação de Ferreira com Brasil e Portugal pode ser experimentada da seguinte maneira:

\footnotetext{
Se, no Brasil, a vitória dos moderados significou uma vitória do pensamento de Ferreira, em Portugal [...] podem ser detectados os ecos do pensamento silvestrino; no encaminhamento da questão da representação - como se deu no Brasil -, na negação tanto do absolutismo quanto do democratismo. (SOUZA, 2009, p.8)
}

Dividida em dois tomos, a organização metodológica do texto segue a forma de "perguntas e respostas", um diálogo jurídico, como propõe o autor. Além disso, a exposição dialógica do trabalho serve para "a instrução da mocidade, que é naturalmente chamada a reconstruir um dia o edifício social que a nos apenas é dado delinear o plano" (FERREIRA, 1843, p.1).

Nas preliminares do texto, ele advertia que o escopo do trabalho era conduzir os leitores de forma ampla sobre o exercício de um código geral. E que o livro foi escrito considerando a materialidade do Código Geral português, aprovado em 1831. 
Em sua primeira parte, o manual faz um balanço dos princípios básicos do direito constitucional. Ao longo de suas 347 páginas, Pinheiro apresentou 12 conferências, que versavam sobre: direitos e deveres do homem e do cidadão, questão territorial, liberdade individual, segurança pessoal, sistema eleitoral, divisão de poderes e administração territorial.

Já o segundo tomo, com 596 páginas, é subdivido em Direito Administrativo e Direito das Gentes, com 12 e quatro conferências, respectivamente. No domínio administrativo, os temas recorrentes são as distintas juntas, a saber: artes e ofícios, comércio, agricultura e mineração, obras públicas, fazenda, justiça, instrução pública, saúde pública, exército, marinha, estadística e garantias subsidiárias.

Nas conferências palco da leitura do objeto, o direito das gentes, tem em sua exposição as seguintes temáticas: dos direitos e deveres das nações durante a paz, dos direitos e deveres das nações durante a guerra, das relações diplomáticas entre as nações e dos agentes diplomáticos. Assim, na interrogação de no 889, “o que he o direito das gentes?”:

\footnotetext{
É o complexo dos princípios por que se devem regular os agentes dos diversos poderes políticos de cada nação, para que nenhum dano seja feito pelos seus membros aos direitos das outras nações. Chama-se também direito público externo ou direito das nações, e divide-se em direito das gentes positivo, e direito das gentes filosófico, natural ou universal. (FERREIRA, 1834, p.312)
}

Em linhas gerais, o direito das gentes, em Pinheiro, funcionaria como se os direitos e deveres dos homens também fosse aplicado às nações. Ademais, ele seguia as orientações dos publicistas, especialistas em direito público e política, principalmente oriundos da modernidade. $\mathrm{O}$ enunciado sobre direito das gentes em Ferreira dialogava com os sentidos de Pufendorf e Bynkershoek no que tange aos agentes dos diversos poderes políticos de cada nação, isto é, uma forma de direito interestadual, no qual a finalidade era que houvesse uma convivência não arbitrária de uma sobre a outra. 
De Vattel ele seguia a inclinação de que o direito das gentes é um exercício de direitos e deveres - direito público externo - aplicado às nações. Assim, como o suíço, Ferreira definia subdivisões no campo do direito das gentes, partindo do que seria o direito positivo. Em sua resposta sobre o que seria o direito das gentes positivo, ele respondia que era "o complexo dos princípios supramencionados que as diversas nações sem quebra de sua independência têm reconhecido, ou expressamente pelos tratados e convenções, ou tacitamente pelos usos e costumes" (FERREIRA, 1843, p.313).

Para Silvestre Ferreira, o direito das gentes positivo aproximava-se daquilo que Vattel classificava como direito das gentes convencional, no qual as nações administravam suas relações internacionais por meio de tratados ou convenções. Esses instrumentos jurídicos, portanto, objetivam normatizar, legalizar e conduzir a relação entre as nações, evitando que "nenhum dano seja feito pelos seus membros aos direitos das outras nações".

Elementos de direito das gentes, de Vicente Ferrer Neto Paiva, foi publicado em 1839 pela Universidade de Coimbra. Homem de muitos capitais simbólicos, era professor catedrático da Universidade de Direito de Coimbra nas cadeiras Direito Universal e das Gentes, assim como associado a distintas acadêmicas de ciências em Portugal. Ademais, Paiva foi deputado vinculado ao cartismo e orientador de juristas portugueses na segunda metade do século XIX, quando arrefeceu sua carreira política.

Seu livro segue com dedicatória ao rei Fernando II, cônjuge de Maria II de Portugal, considerado incentivador das "artes" no cenário português. $\mathrm{O}$ autor notificou os leitores de que o texto era uma operação de escrita jurídica que levava em consideração as matrizes da filosofia do direito da Escola Alemã. Discorria Vicente Paiva: "os Elementos do Direito das Gentes -, que se ensinam seguidamente no mesmo anno, e que tínhamos escripto muito antes de termos conhecimento do estado actual da Philosophia em Alemanha" (PAIVA, 1839, p.1). Considerava tal escola uma vanguarda, que havia sido experimentada em seu livro anterior, denominado Elementos de 
direito natural ou de philosophia de direito, julgando necessário aplicar os autores alemães ao direito das gentes.

Seu objetivo, assim como o de seu conterrâneo, Silvestre Ferreira, era instruir a juventude sobre as regras básicas do direito. Em suas palavras, "temos para nós, que organizados destarte os Elementos de Direito das Gentes, se há de facilitar muito o seu estudo aos nossos discípulos, cujo aproveitamento só temos a peito" (PAIVA, 1839, p.1). Finaliza, portanto, que seu livro atendia à expressão latina Est nobis voluisse satis - Quem quer, já fez metade. A boa vontade supre a obra.

A composição do livro, em 113 páginas, traz cinco divisões. $\mathrm{Na}$ primeira parte, $\mathrm{o}$ autor dedicou-se a compreender os princípios gerais do direito das gentes. No segundo momento, estudou o direito das nações em tempos de paz, enquanto na terceira parte debruçou-se sobre o direito das nações em tempos de guerra. Na quarta parte, os meios de estabelecer, conservar e restabelecer a paz; e, por fim, as pessoas encarregadas de estabelecer, conservar e restabelecer as relações de paz.

Portanto, em seus princípios gerais de direito das gentes, Vicente Ferrer Neto Paiva definia que o "Direito das Gentes é a ciência, que trata das modificações do Direito Natural Puro, aplicado às relações sociais, que existem entre as nações tanto no tempo de paz, como de guerra" (PAIVA, 1839, p.1). De Wolff e Vattel, Paiva racionalizava o direito das gentes como uma ciência responsável por aplicar o direito natural às relações sociais das nações, e que ele deveria ser o norteador tanto em tempos de paz quanto em tempos de guerra. Em linhas gerais, a função desse campo jurídico era evitar os excessos entre as nações.

Em relação ao direito natural puro, o jurista português observou que deveria ser considerado quando o tema eram as relações internacionais. Para ele, o saber do direito natural aplicado ao direito das gentes fazia com que existisse uma harmonia entre as nações. Entretanto, alertou que os críticos do direito das gentes não 
consideravam esse domínio jurídico eficaz na arbitragem entre as nações pela ausência de uma instituição reguladora para tal atividade. Segundo Paiva, "outros têm negado a existência do Direito das Gentes pela falta d'uma instituição, que entre as nações se occupe da execução do Direito e da administração da justiça. Porém estes confundem a existência do Direito com as garantias da sua execução"(PAIVA, 1839, p.2)

Paiva reconhecia o valor da crítica e respondia que já estava em tempos de os países da Europa pensarem um tribunal arbitrário para mediar os interesses das nações, como almejavam alguns filósofos, como o abade de Saint-Pierre e Kant. Em suas palavras:

O Direito das Gentes teria um tribunal, que administrasse justiça entre as nações da Europa, decidindo pacificamente as questões, que se originassem acerca dos seus direitos. As nações da Grécia nos tempos antigos, com a junta dos Amphicteis, as da Alemanha nos modernos, com a Dieta germânica. [...] Os congressos, que por vezes têm reunido, provam, que as nações da Europa tendem para esta instituição, e que sentem a sua conveniência política. (PAIVA, 1839, p.2)

Na esteira dos congressos europeus, Paiva usava as instituições históricas como exemplo para arquitetar uma agremiação que reunisse ou intermediar os interesses das nações. O tribunal de direito das gentes seria possível pelo amadurecimento que as "gentes" da Europa tinham em virtude de seu passado comum. Afinal, desde a Grécia antiga aos distintos congressos europeus pós-modernidade, os europeus têm organizado tratados e convenções entre si que discutiam comércio, casamento, guerra, questões territoriais, navegação, entre outros.

Todavia, a ênfase de Paiva de que "o Direito das Gentes teria um tribunal, que administrasse justiça entre as nações da Europa” e que "as nações da Europa tendem para esta instituição" aproxima-se de um sentimento excludente de que somente a Europa teria seus interesses defendidos. E que as demais nações não estariam preparadas para essa instituição. 
Rocha, no texto "O ideal da paz e o utilitarismo: o europeísmo de Bentham”, discorre que o filósofo utilitarista partia do pressuposto de que o sentimento europeu em comum deveria uni-los em prol dos interesses das "gentes" europeias, determinado pelo "princípio de utilidade ou da maior felicidade do maior número" (ROCHA, 2002, p.463). Segundo Rocha, a criação do tribunal internacional proposto por Bentham deveria discutir "a liberdade de comércio, o abandono das colônias pelas potências europeias, a proibição de alianças ofensivas, a liberdade de imprensa e a supressão do secretismo nos atos políticos e administrativos"(ROCHA, 2002, p.468). E, diferentemente de Paiva, Bentham recusava a interpretação do direito natural oriunda das matrizes do direito das gentes.

Em Princípios de direito internacional, publicado em 1843, Jeremy Bentham faz um estudo em quatro ensaios do que esse campo jurídico deveria abarcar, divididos da seguinte maneira: a primeira seção trata dos “objetos de direito internacional”, seguida, na segunda seção, “de assuntos, ou da extensão pessoal do domínio da lei”; no terceiro ensaio, tratava-se "da guerra considerada em relação às suas causas e consequências"; e, por fim, "um plano para uma Paz Universal e Perpétua” (BENTHAM, 1843, p.1).

Na primeira avaliação, Bentham propõe uma questão em que se um cidadão tivesse de preparar um "código internacional, o que ele iria propor a si mesmo como objeto" (BENTHAM, 1843, p.1). A apresentação segue com uma série de outras indagações de quais deveriam ser o sentimento desse legislador ao fundamentar normas e direitos às nações.

Entretanto, o utilitarista reconhecia que não há qualquer corpo de lei ou instituição jurídica, assim como os demais especialistas do direito das gentes, que tivesse autorização para regular a conduta das nações. No entanto, se fosse ele o cidadão do mundo a escrever um Código Universal que buscasse a "Paz Universal e Perpétua", ele estaria esboçado em cinco objetos, a saber: 
O primeiro objeto do direito internacional para uma determinada nação: [...] consiste em não fazer nenhum prejuízo para as outras nações, respectivamente, tendo em conta o que é próprio de seu próprio bem-estar. 2. Segundo objeto: [...] consiste em fazer o maior bem possível para outras nações, salvando o respeito que é próprio de seu próprio bemestar. 3. Terceiro objeto: [...] consiste em uma determinada nação não receber qualquer prejuízo de outras nações, respectivamente, salvando o respeito devido para o bem-estar dessas mesmas nações. 4. Quarto objeto: [...] consiste em tal estado que recebe o maior benefício possível de todas as outras nações, salvando o respeito devido para o bem-estar dessas nações. [...] 5. Quinto objeto: Em caso de guerra, fazer tais arranjos, que o mal mínimo possível pode ser produzido, de acordo com a aquisição do bem que é procurado. (BENTHAM, 1843, s.p. - Tradução livre)

O direito internacional, em Bentham, estava redigido a partir da noção de "bem-estar". Além disso, os governos deveriam pautar as leis internacionais para evitar prejuízos, ou melhor, torná-los os menores. Nesse sentido, como utilitarista britânico e crítico aos mecanismos de colonização da Inglaterra, os escritos de Bentham mostram a "utilidade do direito internacional". Ou seja, no "lugar de fala" dos bills, a supressão do tráfico seria um meio de garantir o bemestar dos africanos. Já para os brasileiros e portugueses, a leitura do bill era de que essa política só traria prejuízos para suas nações.

Assim, Jeremy Bentham seria o filósofo contraponto dos manuais jurídicos. Considerado uma matriz da lei internacional international law -, ele rompia com as orientações jusnaturalistas dos publicistas, embasadas no direito natural. Para ele, o "direito internacional é uma expressão nova mas fácil de entender, que substitui com vantagem o nome, 'tão impróprio e tão insignificante', de direito das gentes" (ROCHA, 2002, p.466) Ele era ácido em sua crítica a seu campo jurídico por considerar que a relação entre as nações não se dava apenas pelos valores morais do direito natural; estava na cena do jogo o princípio da utilidade pública e privada.

Para ele, a metáfora "a maior felicidade do maior número" deveria ser o norteador da relação entre as gentes. Conforme analisou Rocha: 
[...] a ordem tem o seu fundamento no interesse individual, e daí deduz-se um interesse geral surgido de considerações de utilidade e não de obrigações ou deveres morais; quer dizer, a ordem não resulta duma atitude filantrópica mas diplomática, que move os governantes de um Estado, em razão da própria utilidade, a ter em devida conta os interesses dos demais no momento de atuar na cena internacional. (ROCHA, 2002, p.467)

Apesar de não circular nas referências dos manuais, o princípio utilitarista de Bentham esteve presente nos debates acerca do direito das gentes. Nas fontes analisadas, não há uma condenação do direito natural, nem uma aceitação unânime do utilitarismo. No entanto, na administração da governamentalidade das "gentes", o paralelo entre a valorização da moral e da natureza do homem e os interesses do utilitarismo para supressão do tráfico intercontinental de escravos caminhou na mesma trilha.

A tensão entre os escritos de Bentham e os de Paiva fica evidente quando ele definia que "o direito das gentes é tão válido aos olhos da razão e da justiça como o direito natural, cujas modificações expõem em sua aplicação às relações internacionais" (PAIVA, 1839, p.3). Assim, justiça e natureza humana caminhavam nos escritos do jurista português.

De Martens, Paiva considerou que o direito das gentes partia do princípio de solidariedade ou sociabilidade, não pelo viés utilitário, mas pela "natureza do homem" (PAIVA, 1839, p.3). E que, a partir disso, as relações jurídicas do direito das gentes passavam a ser administradas. Conforme Silvestre Ferreira, Vicente Ferrer Neto Paiva também buscou classificar o direito das gentes, como filosófico e positivo.

O direito das gentes filosófico teria como equivalentes o direito das gentes primitivo ou natural, o direito público externo, o direito internacional, a lei primária das nações ou o direito das gentes por "antonomásia”, que deveria ser executado nas relações internacionais, conforme as matrizes de Vattel, com seu direito das gentes voluntário. Enquanto o direito das gentes positivo ou secundário "resulta dos 
tractados, ou convenções escriptas, e dos usos geralmente observados entre as nações" (PAIVA, 1839, p.3).

Paiva, entretanto, reconhece que a independência das nações dificultava a vivência de um direito das gentes positivo pela ausência de um tribunal que fiscalizasse as regras estabelecidas. Para ele:

\begin{abstract}
A independência das nações obsta a que entre ellas haja um Direito Positivo, na acepção d'esta palavra, pela falta d'um soberano comum, e d'um tribunal, que o aplique. Apesar disto é tal a necessidade, que os homens sentem em suas relações sociais, de regras fixas, que entre as nações da Europa se têm reconhecido não só o Direito Internacional Positivo Público, senão também um Direito Internacional Positivo Particular. (PAIVA, 1839, p.4)
\end{abstract}

Paiva admitia que dentro da Europa "iluminada" e "civilizada" existia o consenso de que as regras de convivência internacional eram importantes para evitar choques de interesses. Uma vez que a existência de um tribunal internacional como desejado por Paiva não ocorreu no século XIX, as nações europeias passaram a aplicar a noção de direito internacional positivo particular, que regulava as relações entre as "grandes sociedades" e estas com as "relações dos indivíduos de diversas nações".

Em linhas gerais, para evitar o desarranjo entre elas, os assuntos que não pudessem ser amplos ao continente deveriam ser negociados em separado. $\mathrm{E}$, se não houvesse um tribunal internacional, o direito das gentes de caráter particular tomou lugar a partir de mecanismos como: tratados, árbitros, mediadores, transações que pudessem estancar a possibilidade de contendas entre as nações. Nesse "tribunal das contendas", partes das negociações se deram por essa via, como o pedido de intermediação de Portugal à França em negociar o tratado com a Inglaterra. Ou a solicitação de permanência das comissões, por parte dos brasileiros, para continuar a julgar as embarcações apreendidas no "infame comércio".

O brasileiro Pedro Autran da Malta Albuquerque, em Elementos do direito das gentes, segundo as doutrinas modernas, teve seu livro editado pela Tipografia União, em 1851, na província de 
Pernambuco. Era professor da Faculdade de Direito de Recife, onde lecionou nas cadeiras de Direito das Gentes e Elementos de Economia Política. Seu trabalho tornou-se referência entre os bacharéis da Faculdade de Recife. Por exemplo, em 1889, em fins do Império, João Silveira de Souza, docente da instituição recifense, publicou Lições elementares de direito das gentes inspirado no compêndio do Dr. Autran.

Para Albuquerque, seu livro era um estudo sobre o direito das gentes a partir das matrizes modernas, e seu intuito era de que ele fosse útil à mocidade do Império, que desejava dirigir-se ao exercício das relações exteriores da pátria. $\mathrm{O}$ arcabouço do livro, constituído de 90 laudas, encontra-se dividido em três partes. Na primeira, ele dedicouse a estudar os direitos absolutos dos Estados; em seguida, os direitos condicionais dos Estados e suas relações pacíficas; e, por fim, o direito dos Estados em suas relações hostis; sendo o estudo do direito das gentes inscrito na primeira seção.

Em suas noções preliminares, o jurista brasileiro esclareceu o que seria o direito das gentes: "O Direito das gentes (direito internacional, ou direito público externo) e o complexo das regras que a razão deduz como conformes a justiça, ou que se fundam em convenções expressas ou tácitas, e que servem de determinar o procedimento das nações entre si.” (ALBUQUERQUE, 1851, p.3)

Com seus pares juristas, Albuquerque argumentava que o direito das gentes estava embasado tanto na lógica positiva da razão quanto na natureza do comportamento do homem. Para ele, o direito das gentes estava dividido entre "natural" e "positivo", e o positivo subdividia-se em "direito pacticio - tratados públicos - $\mathrm{e}$ consuetudinário - costumes com força obrigatória”. Nesse sentido, há em Albuquerque um diálogo com os escritos de Vattel quando ele definia a existência de um direito das gentes convencional e costumeiro, no qual o primeiro operava em primazia sobre os tratados, e o segundo, pelos fundamentos e normas dos acordos entre as nações. 
Sem negar a pertinência do direito natural no desenvolvimento no direito das gentes, Pedro Autran da Malta Albuquerque atribui sentidos distintos para o direito das gentes natural e positivo. Da maneira como ele descreveu, havia a importância do direito das gentes natural, no qual "ele nos ensina as regras de justiça, que as nações devem guardar entre si, não havendo convenções que as modifiquem; porque serve para suprir as lacunas dos tratados e do costume, e promover as mudanças ou alterações, que a boa razão requer". (ALBUQUERQUE, 1851, p. 4). Enquanto o direito das gentes positivo requer uma utilidade.

Essa função consistia em que "as nações, para estabelecerem seus direitos recíprocos, nem sempre se limitam ao simples lume, muitas vezes incerto, da razão humana; e a falta de uma lei geralmente reconhecida recorrem a tratados, e aos usos diuturnos ou costumes, que lhes servem de regra" (ALBUQUERQUE, 1851, p.4)

No meio de importância e utilidade do direito das gentes, o jurista brasileiro não desconsidera as matrizes do direito natural, que consideravam que o direito das gentes era uma aplicação da razão humana às nações. Assim como não descartava a noção de utilitarismo de Bentham. Afinal, a obediência ao direito conforme ele assinalou tinha como intuito "conservar, aperfeiçoar e promover a sua felicidade" (ALBUQUERQUE, 1851, p.4). Ou seja, garantir a maior felicidade, mesmo que no Brasil isso não significasse a todos. Assim, Albuquerque compreendia que a universalização sem um tribunal era uma ação complicada.

Assim como Paiva, Pedro Albuquerque destacou a ausência de tribunais com competência para julgar a contenda entre as nações. Para ele, "entre as nações não há poder judiciário, nem executivo" (ALBUQUERQUE, 1851, p.5). E não cabia ao direito das gentes a atividade de julgar; pelo contrário, esse saber jurídico deveria ser uma ferramenta instrutiva, normatizadora e orientadora na relação entre as nações e seus agentes nacionais.

Sobre a inexistência de uma corte internacional, ele escreveu: 
Ora, se entre as nações não há legislador, nem juiz, nem poder executivo, importa sobre maneira que ellas por todos os meios capazes de suprir a falta de uma legislação escripta determinem os seus direitos; e que na opinião pública e no ânimo dos governos se infunda o sentimento da justiça, e a firme resolução de a guardar fielmente para com os outros, porque esta disposição universal suprirá a falta de um juiz comum. (ALBUQUERQUE, 1851, p.3)

Portanto, para ele caberia às nações acordarem entre si o que seriam os direitos e deveres. Construir uma forma de direito das gentes voluntário, ao estilo de Emmerich von Vattel. No entanto, a dificuldade em estabelecer o que seria considerado justiça ou não no "tribunal das contendas" era um exercício que demandava muita negociação. Afinal de contas, o tráfico intercontinental poderia ser um crime ao direito das gentes natural, condenado moralmente pelos quakers e alguns políticos portugueses e brasileiros, mas era uma questão de direito das gentes particular, na orientação de Vicente Ferrer Neto Paiva, pois tratava de questões internas das "gentes" brasileiras e portuguesas que estavam envolvidas em fazer comércio com as "gentes" africanas.

Nesse sentido, o direito das gentes positivo, de Pedro Albuquerque, presumia que, para harmonizar esses jogos de interesses conflitantes, a "arte de negociar" era o melhor instrumento para evitar a injustiça ou driblar a "falta de um juiz comum" com jurisprudência sobre a ação.

\section{O DISCURSO JURÍDICO DO DIREITO DAS GENTES E O TRÁFICO INTERNACIONAL DE ESCRAVOS}

Ao tornar Ferreira, Paiva, Albuquerque manuais jurídicos comparáveis, operaciona-se a partir de Werner e Zimmermann e as precauções da história cruzada. Para eles, "dispor duas coisas uma sobre a outra em forma de cruz. Daí resulta um ponto de interseção 
onde podem produzir acontecimentos. [...] Essa ideia de intersecção está no princípio da história cruzada" (ZIMMERMANN \& WERNER, 2003, p.95-96). Os autores sintetizam que a noção de interseção contribui para tornar comparáveis os produtos de uma empiria e reflexividade, em que se entrecruzam a materialidade dos corpus documentais e as possibilidades/os problemas que emergem a partir da documentação.

Nesse sentido, os três manuais se entrecruzam ou convergem, inicialmente, na disposição de seus conteúdos. Na materialidade dos livros, as temáticas de "direitos e deveres das nações", sejam em tempos de paz, sejam em tempos de guerra, assim como o comportamento institucional dos agentes diplomáticos, foram apresentadas no desenvolvimento dos textos.

Sobre as noções de direito das gentes, a interseção foi ativada ao instituir que esse campo jurídico cuida das relações entre as nações, e que sua composição era intermediada pelas razões de um direito natural - apesar de Albuquerque não ignorar a lógica de uma utilidade do direito das gentes positivo, que seria responsável pelos tratados, mediações e arbitragem. Essa confluência era capitaneada pelo senso de justiça que uma nação deveria ter para com a outra. $\mathrm{O}$ cerne do problema será como as nações operam com o sentido de justiça interno e de que forma projetavam para o plano internacional. Decorreu disso o fato de o conflito entre o direito das gentes particular ter tensionado as relações de Brasil e Portugal depois das medidas proibitivas promovidas pela Inglaterra com os bills.

$\mathrm{E}$, por último, todos apostam nas subdivisões do direito das gentes: natural ou positivo. O primeiro, com a regra geral da "boa convivência” no cenário internacional, iluminada pela sensatez, civilidade e humanidade, e o segundo, o espaço da vivência ou experiência, no qual as nações se confrontavam por seus interesses, a partir do questionamento das soberanias, buscando tratados, com seus protestos ou reclamações, ou a partir da disciplinarização dos oceanos e da transformação dos antigos "comerciantes de escravos" em novos piratas. E, por fim, convencionando suas concepções de 
justiça e aliança contra aqueles que não se enquadram nos "novos" costumes das nações.

Em relação aos historiadores, o estudo do direito das gentes é um tema pouco recorrente. Sua leitura a partir do tráfico de escravos encontra-se diluída nos trabalhos de história das relações internacionais ou de relações internacionais. Por sua vez, esses dois campos fazem uma leitura da escravidão e das relações internacionais privilegiando questões diplomáticas, fronteiras e políticas internacionais.

Este trabalho não desconsidera os ganhos historiográficos da seara dos internacionalistas, apenas ilumina como o direito das gentes, como um discurso político e jurídico, trouxe políticas normatizadoras e práticas de governamentalidade na organização, fiscalização e disciplinarização que passou a ser a atividade ilícita do "infame comércio". Entretanto, apresento como alguns historiadores têm experimentado o direito como uma matriz discursiva.

Secreto, em $O$ asilo como direito de gentes, estudou como a colonização espanhola aferiu "direito" para as "gentes" - escravos no Novo Mundo. Nas pistas de Francisco de Vitória, ela apontou a existência da noção de "comunidade" entre os povos e que deveria existir um respeito pela "condição humana", conforme sublinhou. Para ela, na Escola Espanhola de direito das gentes havia uma "conclusão bastante genérica de que a condição humana outorgava direitos e que estes direitos pertencem aos povos ou grupos humanos" (SECRETO, 2015, p.2-3).

Entretanto, a escravidão como instituição e a entrada dos europeus no Atlântico foram um obstáculo para o reconhecimento de direito para as distintas "gentes". Nesse sentido, ela destacou que entre portugueses e espanhóis desenvolveu-se um sentido de direito das gentes que respeitava ora os ritos do direito natural, ora a objetividade do direito positivo. Para a autora, esse balanço buscava um "meiotermo", no qual "alguns juristas reconhecem o direito natural - 
imutável e comum a todos os seres humanos - e o direito positivo variável de um lugar para o outro" (SECRETO, 2015, p.3).

Seu diálogo com o direito das gentes é uma forma de elucidar as noções de "solo livre" e "solo escravo" no Novo Mundo. Segundo Secreto, a possibilidade de "solo livre" abriu caminho para a conquista da liberdade dos escravos ao romperem as fronteiras de um país sob regime escravista para outro livre, onde a escravidão já tivesse sido abolida. Essa prática foi analisada a partir dos choques de interpretações entre o que era a definição de asilo ou refúgio e "solo livre". Em suma, a primeira era tema de direito das gentes, enquanto a segunda, uma forma de libertar os escravos do cativeiro.

Em uma análise dos problemas internacionais da escravidão, Grinberg faz três apontamentos, a saber: "a escravidão foi importante no estabelecimento das relações internacionais entre Brasil, Uruguai, Argentina e Peru; os escravos se beneficiaram do conceito de 'solo livre'; a fronteira poderia significar reescravização" (GRINBERG, 2009, p.1). Em linhas gerais, se o regime escravista aproximou os países do Cone Sul americano, também arrefeceu reclamações e protestos internacionais. No texto, Grinberg deixa claro que, se os escravos podiam fugir para países como o Uruguai e a Argentina, que fizeram a abolição da escravidão em 1842 e 1853, respectivamente, os brasileiros "escravistas" também podiam romper as fronteiras para sequestrar os escravos e batizá-los nas terras brasileiras.

Nas querelas sobre a questão escrava que envolveram Argentina e Brasil, a autora sintetizou a reação argentina ao questionamento brasileiro. De acordo com Grinberg: “[...] enfatizar que a prescrição da liberdade para todos os escravos introduzidos de países estrangeiros pelo simples fato de pisar em seu território era um regulamento interno, não podendo, por esta razão, 'dar motivo de queixa ou ofensa a nenhum governo estrangeiro" (GRINBERG, 2009, p.4)

Para evitar uma disputa internacional com o Brasil, o governo de Buenos Aires devolvia os escravos fugidos que haviam sido reclamados pelo Brasil. Todavia, salientava que o decreto argentino era uma causa de direito público interno, e não passivo de queixa de 
outros países. Grinberg conclui, portanto, que o "solo livre" e o "solo escravo" forneceram possibilidades de ações de liberdade, assim como de escravidão, além, é claro, de aquecer contendas entre os países vizinhos.

Lima faz uma leitura do direito das gentes e da escravidão considerando o jogo diplomático entre Brasil e Uruguai em 1867. O fio condutor da trama foi a disputa pela fuga de um escravo para a residência do enviado uruguaio André Lamas, na região de Botafogo. Para ele, Lamas, “como ministro público em solo estrangeiro, ele e sua missão possuíam prerrogativas especiais afiançadas pela prática internacional e respaldadas pelo direito das gentes” (LIMA, 2015, p.141). Assim, a apreensão do escravo constituía um atentado às regras do direito das gentes.

Usando Vattel como matriz discursiva do direito das gentes, no qual o objetivo desse campo jurídico é "estabelecer solidamente as obrigações e os direitos das nações” (LIMA, 2015, p.147), Lima adverte que Lamas utilizou esse episódio para contrapor os "maus costumes" brasileiros no que tange à permanência da escravidão. Para ele, o direito das gentes era "extremamente utilitário" na campanha liberal e anti escravista. E, para fundamentar sua crítica, o enviado uruguaio espargia seus conhecimentos a partir de Vattel com a seguinte observação:

\footnotetext{
Prova-se em direito natural que todos os homens recebem da natureza uma liberdade e uma independência que não podem perder senão por consentimento deles próprios [...]. É preciso, pois, aplicar às Nações as regras do direito natural, para descobrir quais são os direitos e obrigações que lhes dizem respeito. Portanto, o direito das gentes não é originariamente senão o direito da natureza aplicado às Nações. (LIMA, 2015, p.152)
}

Nesse sentido, deve-se dizer que, para Lamas, o episódio de apreensão do escravo foi utilizado para criticar a escravidão no Brasil, assim como para apontar que se no âmbito do direito interno a escravidão ainda vigorava, no plano internacional os esforços do Brasil para aboli-la ainda engatinhava. 
Em $O$ direito natural e das gentes e ofederalismo no processo de independência na América, Padoin se propõe discutir qual foi a importância desse domínio jurídico na composição teórica dos Estados nacionais na América e a defesa dos projetos federalistas. Ao longo do trabalho, ela expôs diferentes pensadores do direito das gentes, em um esforço de Francisco de Vitória a Georg-Friedrich Von Martens, que para ela estendeu os estudos de direito das gentes europeu para a América. Nesse sentido, concluiu que:

O Direito Natural e das Gentes, através de sua evolução e divulgação, acompanhou o desenvolvimento do Estado [...]. Foi um dos grandes responsáveis pela tomada de consciência da igualdade dos direitos, [...] e a necessidade importância e do pacto político entre as sociedades ou Estados para combater a exploração colonialista e o poder tirânico, por exemplo, como também para garantir os direitos individuais e coletivos desta sociedade política e suas formas de associação pactual ou contratual. (PADOIN, 2013, p.129)

De fato, o direito das gentes foi um saber que auxiliou os governos na construção de suas políticas "públicas" de caráter internacional. E, no caso americano, foi utilizado para fazer frente às políticas europeias no continente (vide a Doutrina Monroe, em 1823). Entretanto, pensar em uma "igualdade dos direitos" pela via do direito das gentes no espaço americano foi um exercício jurídico que ficou para se fazer. Reconhecia-se que a escravidão era condenada, moralmente, pelo direito natural e que o direito das gentes não a legitimava, mas nem por isso as nações americanas fizeram processos abolicionistas em cadeia. O exemplo disso foi o Brasil, que a manteve até 1889, e até mesmo os Estados Unidos, até 1863.

Silva, em O tráfico de escravos nas relações externas de Brasil e Portugal, tem proximidade com este trabalho. Silva estudou como Brasil e Portugal se comportaram no cenário internacional a partir das políticas de supressão do tráfico de escravos. Entretanto, nossos trabalhos diferem quanto ao uso dos corpus documentais. Ele debruçou-se na documentação dos Ministérios dos Negócios Estrangeiros e nos papéis das Comissões Mistas entre Brasil e Grã- 
Bretanha. O texto deste trabalho também analisará os relatórios ministeriais, assim como os manuais jurídicos de direitos das gentes, entrecruzando com as discussões britânicas sobre os bills. E discutirá os textos políticos do visconde Sá da Bandeira e de João Manoel Pereira da Silva, um deputado brasileiro.

Para ele, se a Independência do Brasil e a disputa pelo trono português fizeram com que as relações diplomáticas entre Brasil e Portugal se esfriassem, isso não se repetia nas transações escravistas, que permaneciam aquecidas. No jogo escravista internacional,

Silva definia os laços luso-brasileiros, sendo o Brasil o receptor, e Portugal, o fornecedor. O primeiro recebendo as distintas "africanidades" das colônias portuguesas na África, e o segundo, na prática da ilegalidade e em muitos casos sob as vistas das governanças ultramarinas, permitindo o fornecimento de uma mão de obra cara ao Brasil.

Dessa relação diplomática, ele ponderou que:

\begin{abstract}
A questão primordial era a representatividade do tráfico na economia portuguesa e na economia brasileira. A imensa maioria dos negreiros estavam sediados no Rio de Janeiro, mas muitos tinham nacionalidade portuguesa e isto gerava recursos que eram destinados à economia portuguesa [...]. Para o Brasil o impacto é bastante conhecido, além de trazerem braços à lavoura, os traficantes constituíam capital, que muitas vezes era utilizado para financiar a própria lavoura (SILVA, 2014, p.4).
\end{abstract}

Se, pelo lado dos arranjos institucionais, os governos de Lisboa e do Rio de Janeiro andavam fragilizados, entre os homens, ou melhor, entre os negociadores e os negociantes da escravidão existia solidariedade. Entretanto, a política contra a escravidão - da legitimação do direito das gentes, das ações britânicas e da filantropia - causou na primeira metade do século XIX brasileiro e português um desafio para burlar a disciplinarização e as práticas de governamentalidade que foram impressas nas duas margens do oceano. Era chegado o tempo, portanto, de mudar, ou seja, de pensar 
novos rumos para o tráfico intercontinental de escravos, que estava agonizando.

\section{CONSIDERAÇÕES FINAIS}

Pelo exposto, os manuais de direito das gentes foram importantes para situar o sentido que as nações brasileira e portuguesa usaram para contestar os bills promovidos pela Inglaterra. A lógica de que eles se configuraram como um campo jurídico no qual as nações deveriam aplicar o respeito entre si com base na justiça e na soberania foi a via escolhida para administrar a contenda jurídica criada neste tribunal. Em suma, uma judicialização internacional da política da escravidão no plano internacional.

Portanto, esses enunciados jurídicos serviram para mostrar como eram as regras desse mosaico discursivo que se tornou o tribunal das contendas. Por fim, conhecer e operar com as ferramentas do direito das gentes foi um caminho empregado pelas nações em disputa sobre a legalidade ou não da supressão do tráfico de escravos pelo Atlântico Sul.

Portanto, as considerações finais do artigo foram de que o discurso jurídico do direito das gentes foi fundamental na operação internacional que desarticulou o tráfico de escravos (Inglaterra), assim como, foi utilizado para defesa dos interesses dos países que dependiam da mão-de-obra escrava de origem africana (Brasil, Portugal e suas colônias na África). Ao pesquisar os manuais jurídicos também se conclui que o mundo da política mantinha relação dialógica com a produção da literatura jurídica. Afinal, os políticos, assim como, os representantes internacionais devem conhecer as regras desse mosaico discursivo. 
Data de Submissão: 05/02/2019

Data de Aprovação: 14/04/2020

Processo de Avaliação: double blind peer review

Editor Geral: Jailton Macena de Araújo

Editor de Área: Jailton Macena de Araújo

Assistente Editorial: Maria Aurora Medeiros

\section{REFERÊNCIAS}

ACCIOLY, Hildebrando et al. Manual de direito internacional público. São Paulo: Saraiva, 2011.

ALBUQUERQUE, Pedro Autran da Malta. Elementos do direito das gentes. Pernambuco: Tipografia União, 1851.

ALMEIDA, Paulo Roberto de. Formação da diplomacia econômica no Brasil: as relações internacionais no Império. São Paulo: Senac; Brasília: Funag, 2005.

BENTHAM, Jeremy. Principles of international law. In: Works of Jeremy Bentham. Ed. J. Bowring, Edinburg: William Tait, 1843. v. II. Disponível em:

http://www.laits.utexas.edu/poltheory/bentham/pil/pil.eo1.html. Acesso em 14 jan.2019.

BOSON, Gerson de Brito Mello. Direito internacional público. Belo Horizonte: Del Rey, 1994.

CERVO, Amado Luiz; BUENO, Clodoaldo. História da política exterior do Brasil. São Paulo: Ática, 1992.

DELGADO, Érika Melek. Identidades em trânsito: o caso dos africanos livres na primeira colônia britânica da África Ocidental. Revista de Ciências Humanas, Viçosa, v. 14, n. 2, 2014. Disponível em: http://www.cch.ufv.br/revista/pdfs/vol14/artigo5dvol14-2.pdf. Acesso em 14 jan.2019.

FERREIRA, Silvestre Pinheiro. Manual do cidadão em um governo representativo, ou principios de direito 
constitucional, administrativo e das gentes. Paris: Rey et Gravier/J. P. Aillaud, 1834. v. 2.

FLORES, Alfredo. Algumas reflexões sobre o método de estudo de caso no direito. Revista Quaestio Iuris, v. 4, n. 1, 2011. Disponível em: http://www.e-

publicacoes.uerj.br/index.php/quaestioiuris/article/view/10210/798 $\underline{8}$ Acesso em 14 jan.2019.

FOUCAULT, Michel. Arqueologia do saber. Tradução de Luiz Felipe Baeta Neves.7. ed. Rio de Janeiro: Forense Universitária, 2009.

FOUCAULT, Michel. As palavras e as coisas. Tradução de Salma Tannus Muchail. 4. ed. São Paulo: Martins Fontes, 1987.

GRINBERG, Keila. Escravidão e relações diplomáticas Brasil e Uruguai, século 19. In: 4 ENCONTRO ESCRAVIDÃO E LIBERDADE NO BRASIL MERIDIONAL. Anais... Curitiba: UFPR, 2015.

LETWIN, Shirley Robin. On the history of the idea of law. Cambridge University Press, 2005.

LIMA, Rafael Peter de. Diplomacia em xeque: direito das gentes e escravidão na agenda bilateral Brasil-Uruguai. Revista História e Cultura, Franca, 2015.

MALTEZ, José Adelino. Princípios de ciência política: o problema do direito. Lisboa: ISCSO, 1998.

MAMIGONIAN, Beatriz Gallotti. Une modernité imposée et ambigué: la Grande-Bretagne, le Brésil et le projet d'abolition de la traite 1848-1851. In: REIS, Daniel Aarão; ROLLAND, Denis (Coord.). Modernités nationales, modernités importées. Paris: L'Harmattan, 2012.

MATTOSO, Kátia M. de Queirós. Ser escravo no Brasil. Tradução de James Amado. São Paulo: Brasiliense, 2003.

PAIVA, Vicente Ferrer Neto. Elementos de direito das gentes. Lisboa: Universidade de Coimbra, 1839.

ROCHA, Acílio da Silva Estanqueiro. O ideal da paz e o utilitarismo: o europeísmo de Bentham. Barcelona: Universitat, 2002. Sep. de "Retos de larazónpráctica", 2002.

ROUSSEFF, Dilma. Discurso da presidenta da Republica Dilma Rousseff na abertura do debate geral da $68^{\mathrm{a}}$ Assembleia Geral das Nacoes Unidas em Nova Iorque, EUA, Planalto, 24 set. 2013. Disponível em: http://www.itamaraty.gov.br/pt-BR/discursosartigos-e-entrevistas-categoria/presidente-da-republica-federativado-brasil-discursos/5898-discurso-da-presidenta-da-republica- 
O Direito Das Gentes Como Discurso: 0 Tráfico Internacional De Escravos Sob A...

dilma-rousseff-na-abertura-do-debate-geral-da-68-assembleia-geraldas-nacoes-unidas-nova-iorque-estados-unidos-24-de-setembro-de2013. Acesso em 14 jan.2019.

SECRETO, Maria Verónica. O asilo como direito de "gentes" na tradição espanhola. In: 7o ENCONTRO ESCRAVIDÃO E LIBERDADE NO BRASIL MERIDIONAL. Anais... Curitiba: UFPR, 2015 .

SILVA, Leonardo Bruno. O tráfico de escravos nas relações externas de Brasil e Portugal. Tese (Doutorado) - Faculdade de Ciências e Letras de Assis, Unesp, São Paulo, 2014.

SOUZA, Alexandro Ferreira. Silvestre Ferreira e o pensamento político luso-brasileiro do século XIX. Revista de Estudos Filosóficos da UFSJ, São João del-Rei, n. 3, p. 8, 2009.2.

Disponível em:

http://www.ufsj.edu.br/portal2repositorio/File/revistaestudosfilosof icos/art2-rev3.pdf Acesso em 14 jan.2019.

VATTEL, Emer de. O direito das gentes. Brasília: UnB/Instituto de Pesquisas das Relações Internacionais, 2004.

ZIMMERMANN, Benédicte; WERNER, Michael. Pensar a história cruzada: entre empiria e reflexibilidade. Textos de História, v. 11, n. 1-2, 2003. 


\title{
The Law Of The People As A Discourse: The International Slave Trade In The Light Of Legal Knowledge (1839-1850)
}

\author{
Juliana de Castro Costa
}

\section{Gustavo Pinto de Sousa}

\begin{abstract}
This article aims to analyze the legal literature on the law of the people and their legal effects in the international debate on the suppression of the slave trade. In this sense, the analysis will pursue how the literature of 19th century law manuals focused on the elements of People's Law to guide legal disputes in relation to the international rules of nations in the 19th century. Therefore, the stage of the People's Law disputes will take into account the political and legal disputes that involved countries like Brazil, Portugal and England with regard to the problems regarding the interruption of the slave trade by the waters of the South Atlantic. In methodological terms, the text starts from the contributions of discourse analysis on the French side. The production of legal meanings in relation to People's Law is illuminated in the sources. In addition, the article will illuminate an interdisciplinary and methodological intersection between History and Law by taking the Law of the People as a discourse / knowledge. Finally, the text will present how the rules of international law were used to give a sense of legality, legitimacy and justice in relation to the permanence or not of the international slave trade.
\end{abstract}

Keywords: International Law. International Trafficking of Slaves. Historical and legal comparison. Discourse. 